\title{
Determination of Survivable Fires
}

\author{
D. L. Dietrich;, J. E. Niehaus, G. A. Ruff, D. L. Urban \\ NASA John H. Glenn Research Center, Cleveland, Ohio, 44135, USA \\ F. Takahashi, J. W. Easton, A. A. Abbott \\ National Center for Space Exploration Research, Cleveland, Ohio, 44135, USA \\ J. C. Graf \\ NASA Lyndon B. Johnson Space Center, Houston, Texas, 77058, USA
}

At NASA, there exists no standardized design or testing protocol for spacecraft fire suppression systems (either handheld or total flooding designs). An extinguisher's efficacy in safely suppressing any reasonable or conceivable fire is the primary benchmark. That concept, however, leads to the question of what a reasonable or conceivable fire is. While there exists the temptation to 'over-size' the fire extinguisher, weight and volume considerations on spacecraft will always (justifiably) push for the minimum size extinguisher required. This paper attempts to address the question of extinguisher size by examining how large a fire a crew member could successfully survive and extinguish in the confines of a spacecraft.

The hazards to the crew and equipment during an accidental fire include excessive pressure rise resulting in a catastrophic rupture of the vehicle skin, excessive temperatures that burn or incapacitate the crew (due to hyperthermia), carbon dioxide build-up or other accumulation of other combustion products (e.g. carbon monoxide). Estimates of these quantities are determined as a function of fire size and mass of material burned. This then becomes the basis for determining the maximum size of a target fire for future fire extinguisher testing.

\section{Introduction and Background}

Future exploration missions call for extending a human presence into space beyond low Earth orbit where, in the event of an emergency, a rapid return to earth is not an option. An accidental fire is an emergency situation that can easily have dire consequences if it is not detected and extinguished quickly and effectively. Therefore, the crew must have the equipment, systems, and procedures to safely deal with any possible fire and its after-effects. The first line of defense in a fire safety strategy is fire prevention through material selection and control. Experience in manned space flight, however, indicates that this control may, but will not necessarily, ensure that fires on spacecraft will not occur. Therefore, fire detection and suppression systems are still required ${ }^{\mathrm{a}}$.

Fortunately accidental fires have been very rare on space vehicles. There are, however, open questions about the size of a potential fire in spacecraft. For total flooding agents involving an inert gas, it is a relatively simple exercise to compute the required mass of suppressant given the concentration needed to suppress a fire irrespective of fire size. Detailed Computation Fluid Dynamic (CFD) simulations of suppressant dispersal would provide an even better tool to design the suppressant system. In practice the dispersal of an inert gas suppressant to a concentration required to suppress a likely fire would result in a vehicle over-pressure and an oxygen concentration too low for crew survival. Therefore, inert gas suppressants are not necessarily an optimal solution for a spacecraft suppression system. ${ }^{1-3}$

Streaming or local application agents can safely and quickly extinguish many fires. As a result, all NASA and most foreign manned spacecraft provide a hand-held extinguisher. The size of these extinguishers,

\footnotetext{
*Aerospace Engineer, NASA John H. Glenn Research Center, Cleveland, Ohio 44135, AIAA Member.

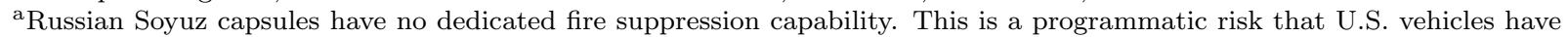
not accepted since the Mercury and Gemini programs.
} 
however, is typically based on terrestrial fire standards and not the unique properties of microgravity fires and hazards of the spacecraft environment. The temptation of the designers is to 'over-size' the extinguisher to compensate for any uncertainty in fire size or severity. Severe weight and volume limitations, however, will always push back on the 'over-size' design idea. Recently, we introduced the concept of a 'survivable fire' to guide the design and qualification of a hand-held fire extinguisher for future spacecraft. ${ }^{4}$ In this paper we expand on this concept and discuss in detail the specific risks to the crew and introduce estimates to their severity.

\section{Crew and Vehicle Risks from Fire}

In order for a fire to occur, all three elements of the fire triangle must be present, fuel, oxygen and an ignition source. In a manned spacecraft, the first two will invariably be present, even with very strict material controls. The ignition source can be a number of things, nearly all of which are the result of equipment malfunction. Assuming there is a release of energy sufficient to initiate a fire, the chemical reaction between the fuel and oxygen will result in heat release $\dot{\mathcal{Q}}_{\text {сомB }}(t)$. The time dependence emphasizes the fact that, assuming sufficient fuel and oxygen, the flame will grow with time after ignition. As the fire burns, it consumes fuel and oxygen, produces carbon dioxide and water vapor and releases heat. The process presents some very real hazards to the crew.

\section{II.A. Carbon Dioxide Toxicity}

Carbon dioxide $\left(\mathrm{CO}_{2}\right)$, a product of both fire and human metabolism, is a threat to human health in high enough concentrations. The Spacecraft Maximum Allowable Concentration (SMAC) ${ }^{5}$ for carbon dioxide provides a guide for determining a limit. The level is currently a maximum of $2.0 \%$ for 1 hour and $1.3 \%$ for 24 hours.

A critical component of all spacecraft environmental systems is the scrubbing system for carbon dioxide. These systems are designed to remove the metabolically produced carbon dioxide from the spacecraft atmosphere. For reference, individual carbon dioxide production can vary from 0.5 to $4.0 \mathrm{l} / \mathrm{min}$ at ATP (atmospheric or room temperature and pressure conditions, $20 \mathrm{C}$ and $1 \mathrm{~atm}$, respectively) from rest to moderately strenuous exercise. In comparison, a birthday candle produces approximately $0.18 \mathrm{l} / \mathrm{min}$ of carbon dioxide at ATP conditions (burning in normal gravity). So while the spacecraft Environmental Control and Life Support Systems (ECLSS) can remove carbon dioxide, in the event of a fire, the carbon dioxide production could exceed the removal capability of the ECLSS and it would accumulate to dangerous levels.

If the heat release profile of the flame, $\dot{\mathcal{Q}}_{\text {сомB }}(t)$, is known or assumed, then the carbon dioxide accumulation rate $\left(\left[\dot{n}_{C O 2}(t)\right]_{\text {acc }}\right)$ is simply

$$
\left[\dot{n}_{C O 2}(t)\right]_{\mathrm{acc}}=\frac{\dot{\mathcal{Q}}_{\mathrm{COMB}}(t)}{Q_{\text {comb }}} \frac{\nu_{C O 2}}{\mathcal{M}_{O 2}}-\left[\dot{n}_{C O 2}(t)\right]_{\mathrm{ECLSS}}
$$

where $Q_{\text {comb }}$ is the heat generation per mass of oxygen consumed, $\mathcal{M}_{\mathrm{O} 2}$ is the molar mass of oxygen, $\nu_{\mathrm{CO} 2}$ is the stoichiometric coefficient that represents the number of moles of carbon dioxide produced per mole of oxygen consumed and $\left[\dot{n}_{C O 2}(t)\right]_{\text {ECLSS }}$ is the rate of carbon dioxide removal by the vehicle ECLSS. For this study, we assume $Q_{\text {comb }}=13,100 \mathrm{~kJ} / \mathrm{kg}_{\mathrm{O} 2}$ typical for a wide range of fuels and a fuel with an average molecular composition of $\mathrm{C}_{6} \mathrm{H}_{10} \mathrm{O}_{5}{ }^{6,7}$ The mole fraction of carbon dioxide is then simply the integrated molar mass $\left(\int_{t=0}^{t}\left[\dot{n}_{C O 2}(t)\right]_{\text {acc }} d t\right)$ normalized by the total molar mass of gas in the vehicle.

\section{II.B. Excessive Temperature}

A fire in an open cabin releases a significant amount of energy to the spacecraft cabin. The high temperatures from this energy release pose two significant hazards to the crew and vehicle. The first is the immediate hazard of heat flux or high temperature gas from the fire burning that either burns the crew or damages critical spacecraft life support systems. The burns could be external (skin) from the flame radiant flux or internal (lung and airways) from inhalation of high temperature gas. The second is the longer-term effect of a high temperature environment that could severely injure the crew by creating a hyperthermic environment. 


\section{II.B.1. Excessive Heat Flux}

An immediate hazard posed by any fire is skin burns and damage to the lungs and airways from inhaling high temperature gas. The threat is obviously greater the closer the crew is to the flame. For human-crewed spacecraft, this poses two unique threats. First, the small volume of a spacecraft greatly limits the distance the crew can be from the fire. Second, in microgravity, the heat flux and gas temperature will not have the strong directional dependence that a flame in normal gravity has.

Assuming the heat flux from a flame with size $\dot{\mathcal{Q}}_{\text {ComB }}(t)$ is present in the cabin, the heat flux a distance $r_{\text {crew }}$ from the flame is

$$
\dot{q}_{\text {crew }}(t)=\frac{\eta \dot{\mathcal{Q}}_{\text {сомB }}(t)}{2 \pi r_{\text {crew }}^{2}}
$$

In this expression, we assume that the flame power is transferred into a hemisphere as if the flame is against a solid insulating surface (with no heat loss). The term $\eta$ is a factor between 0.0 and 1.0 that simply accounts for any heat transfer to a solid surface or directional component of the heat transfer. With a heat flux given by Equation 2 above, it becomes a matter of understanding the magnitude of the threat to the crew.

Stoll and Chianta ${ }^{8}$ provide data on the time to a second degree burn as a function of heat flux to the skin. Second degree burns involve redness and blistering of the skin and depending on the severity can result in serious infections. They typically take several weeks to heal. A second degree burn over a large portion of a crew member's body would represent very serious medical concern. We use this data as a guide for the maximum exposure time and consider that it would take the crew on the order of approximately 60 seconds to extinguish a fire.

Understanding the threat to the crew due to excessively high temperature inhaled air again assumes that the energy released by the fire is distributed symmetrically around the fire. If we assume that the fire occupies a volume with a given radius $\left(r_{\mathrm{FIRE}}\right)$, then the steady-state radial distribution of temperature $\left(T_{g}(r)\right)$ is

$$
T_{g}(r)=\left(\frac{r_{\mathrm{FIRE}}}{r}\right)\left(\frac{r_{\mathrm{CABIN}}-r}{r_{\mathrm{CABIN}}-r_{\mathrm{FIRE}}}\right) T_{\mathrm{FIRE}}+\left(\frac{r_{\mathrm{CABIN}}}{r}\right)\left(\frac{r-r_{\mathrm{CABIN}}}{r_{\mathrm{CABIN}}-r_{\mathrm{FIRE}}}\right) T_{\mathrm{CABIN}},
$$

where $r_{\text {CABIN }}$ and $T_{\text {CABIN }}$ are the approximate radius and temperature of the spacecraft and $T_{\text {FIRE }}$ is the temperature of the fire. ${ }^{9}$ The heat-release rate of the fire $(\dot{\mathcal{Q}}(t))$ is

$$
\dot{\mathcal{Q}}(t)=\frac{\left(T_{\mathrm{FIRE}}-T_{\mathrm{CABIN}}\right) r_{\mathrm{CABIN}} r_{\mathrm{FIRE}}}{4 \pi \lambda_{g}}
$$

where $\lambda_{g}$ is the thermal conductivity of the gas, assumed to be air at one atm pressure and ambient temperature.

Lva and co-workers ${ }^{10}$ performed a detailed analysis of tracheal burning from inhaled heated gas. Their analysis used a maximum inhaled gas of approximately $373 \mathrm{~K}$ as the base for the computation and predicted significant damage immediately after exposure and more serious damage to deeper tissue after a longer exposure. We therefore consider this to be the temperature limit for short duration exposure.

\section{II.B.2. Hyperthermic Environment}

In the event of an accidental fire, the heat release will cause a temperature rise in the cabin. The primary mechanism to dissipate the heat from the cabin gas is radiation and convection heat transfer to the vehicle (assumed to be at a constant temperature) and through the ECLSS systems. While the immediate concern in the event of a fire is burn injuries to the crew and damage to the vehicle, there is also a risk to the crew in the long-term if the cabin temperature remains too high for too long. The cabin gas temperature as a function of time $\left(T_{g}(t)\right)$ is simply

$$
C_{v, g} \frac{d\left(n_{\mathrm{CABIN}} T_{g}\right)}{d t}=\dot{\mathcal{Q}}_{\mathrm{COMB}}(t)-a_{P} V_{\mathrm{FIRE}} \sigma\left(T_{f}^{4}-T_{w}^{4}\right)-h_{\mathrm{CABIN}} A_{\mathrm{CABIN}}\left(\bar{T}_{g}-T_{w}\right)
$$

where $C_{v, g}$ is the average (constant volume) specific heat of the gas, $n_{\text {CABIN }}$ is the molar mass of gas in the cabin and $\dot{\mathcal{Q}}_{\text {сомв }}$ is the combustion heat-release rate. The second term on the right hand side of Equation 5 is the radiative heat transfer between the flame and the walls of the cabin. The expression includes radiative 
transfer ( $\sigma$ is the Stefan-Boltzman constant) from combustion-produced carbon dioxide and water vapor through the Planck Mean Absorption Coefficient $\left(a_{P}\right)$, but neglects solid particulate heat transfer. The third term on the right hand side of Equation 5 is the convective heat transfer (with heat transfer coefficient $h_{\text {CABIN }}$ ) between the cabin air and the walls of the cabin (with area $A_{\text {CABIN }}$ and volume $V_{\text {CABIN }}$ assumed to be at a constant temperature). For the sample calculations herein, we assume that the volume of the fire $\left(V_{\text {FIRE }}\right)$ is the volume of the cabin $\left(V_{\text {CABIN }}\right)$.

Hyperthermia results when the body's compensatory mechanisms cannot dissipate the excess metabolic energy. It is a complex problem beyond the scope of the present analysis, but can occur at temperatures as low as $311 \mathrm{~K}$. For the present analysis, however, we assume a properly hydrated, physically fit crew and that hyperthermia will occur if the cabin gas temperature remains above $330 \mathrm{~K}$ for longer than 60 minutes.

\section{II.C. Vehicle Over-pressurization}

As a flame burns in the sealed volume of a spacecraft, the temperature rise in the cabin as detailed in Section II.B.2 will result in a pressure rise. At some point, the cabin pressure will exceed the capabilities of the vehicle and the pressure relief system will vent gases from the cabin to space to maintain the structural integrity of the vehicle. If the pressure rise is too rapid and exceeds the pressure relief capability of the vehicle a catastrophic structural failure could occur.

The pressure rise associated with the fire is inconsequential to the health of the crew, the hazard is to the health of the spacecraft. While activating the pressure-relief system is not desired, it is certainly preferable to a rupture of the spacecraft structure. The pressure in the cabin $\left(P_{\text {CABIN }}\right)$ is simply related to the temperature through the ideal gas law assuming the volume of the spacecraft is known.

$$
P_{\text {CABIN }}=\frac{n_{\text {CABIN }} \mathcal{R} u T_{g}}{V_{\text {CABIN }}}
$$

where $\mathcal{R} u$ is the universal gas constant. Gokoglu and co-workers ${ }^{11}$ performed a detailed analysis for a largescale fire experiment proposed for an ISS re-supply vehicle (e.g. HTV, ATV, etc.) using this approach and achieved good agreement with experimental data (albeit in much smaller chambers).

\section{II.D. Oxygen Depletion}

Fire consumes oxygen and thus will compete with the crew for the available oxygen in the cabin. In the reduced gravity environment of space (or even the Moon or Mars), a fire can burn to relatively low oxygen mole fractions before it will extinguish. ${ }^{1-3}$ The exact limit depends on the material burning and other environmental factors (e.g., air speed) but in general, the flame will burn at oxygen concentrations that are unsuitable for human survival. Therefore, any consideration of a survivable fire should include an analysis of the oxygen consumption. The molar depletion of oxygen is

$$
\left[\dot{n}_{O 2}(t)\right]_{\mathrm{acc}}=\frac{\dot{\mathcal{Q}}_{\mathrm{comB}}(t)}{Q_{\text {comb }}} \frac{\nu_{O 2}}{\mathcal{M}_{O 2}},
$$

where $Q_{\text {comb }}$ is the heat generation per mass of oxygen consumed, $\mathcal{M}_{\mathrm{O} 2}$ is the molar mass of oxygen, $\nu_{\mathrm{O} 2}=1$ (the stoichiometric coefficient for oxygen. The mole fraction of oxygen is then simply the integrated molar mass $\left(n_{O 2}(t=0)-\int_{t=0}^{t}\left[\dot{n}_{C O 2}(t)\right]_{\text {acc }} d t\right)$ normalized by the total molar mass of gas in the vehicle.

\section{II.E. Atmospheric Contamination}

The primary products of combustion are carbon dioxide and water vapor. The analysis above assumes complete reaction and is a reasonable assumption for total heat release and carbon dioxide production. The high temperatures during combustion, however, also result in incomplete oxidation of the fuel (especially for under-ventilated flames) and the production of gaseous products and particulates that can be dangerous to the crew. The most common of these pollutants is carbon monoxide. There are, however, a host of other products that are of concern. The threat to the crew can be immediate in the case of carbon monoxide or a longer-term concern to crew health (e.g., lung damage from smoke particulate).

For this initial analysis, we only consider the production of carbon monoxide and carbon dioxide as other gaseous and particulate species require a detailed specification of the burning material. Predicting carbon monoxide from a generic 'fire' without a specification of the material and environment is difficult. The best 
approach is to consider the chemical equilibrium ${ }^{12}$ of a mass of fuel $\left(m_{f}\right)$ reacting with a specified mass or volume of oxygen. The analysis considers poly-methylmethacrylate (PMMA, $\left[\mathrm{C}_{5} \mathrm{H}_{8} \mathrm{O}_{2}\right]_{n}$ ) as the fuel with air as the oxidizer. The balanced chemical equation for methacrylate is

$$
\mathrm{C}_{5} \mathrm{H}_{8} \mathrm{O}_{2}+6 \mathrm{O}_{2} \rightarrow 5 \mathrm{CO}_{2}+4 \mathrm{H}_{2} \mathrm{O},
$$

which means the stoichiometric molar ratio of fuel to oxidizer is $(1 / 6)$. The equivalence ratio $(\phi)$ is the ratio of the actual fuel to oxidizer ratio to the stoichiometric fuel to oxidizer ratio. For the reaction system considered, the fuel to air ratio $(\mathrm{F} / \mathrm{O})$ is

$$
(\mathrm{F} / 0)=\frac{\left(m_{f} / \mathcal{M}_{f}\right) \mathcal{M}_{\text {air }}}{0.21 V_{\text {CABIN }} \eta \rho_{\text {air }}}
$$

where $m_{f}$ is the mass of PMMA, $\mathcal{M}_{f}$ and $\mathcal{M}_{\text {air }}$ are the molar masses of the fuel and air, respectively, $\rho_{\text {air }}$ is the density of air and $\eta$ is a factor between 0 and 1.0 that representing the fraction of cabin air that participates in the reaction.

The results presented herein use $-184.5 \mathrm{~kJ} / \mathrm{gmol}$ for the heat of formation of the fuel. ${ }^{7}$ The chemical equilibrium calculation ${ }^{12}$ then produces estimates of the mixture temperature and mole fractions of carbon dioxide and carbon monoxide. The analysis then assumes that this burned mixture of gases mixes uniformly throughout the cabin to produce estimates of the gas temperature and carbon dioxide and carbon monoxide mole fractions.

\section{Results and Discussion}

The analysis in the previous section allows us to estimate the risks to the crew and vehicle from the various hazards imposed by an accidental fire. The computations are strongly dependent on the size of the vehicle. For reference, we assume a sealed volume the approximate size of the Destiny module on the International Space Station (ISS). The assumed volume (approximate gas volume) and surface area (approximate internal surface area) are $65 \mathrm{~m}^{3}$ and $150 \mathrm{~m}^{2}$, respectively.

Equation 5 is a simple first order ordinary differential equation easily solved after specifying the fire power $\left(\dot{\mathcal{Q}}_{\text {сомB }}(t)\right)$. We assume a fire that grows with a growth coefficient ${ }^{13}$ of $0.0029 \mathrm{~kW} / \mathrm{s}^{2}$ which is consistent with a slow growing fire. The fire grows for a preset period of time, remains at a constant power for a specified time and then reduces to 0 (an extinguished fire) for another specified time period. Specifying the fire power also then allows the computation of cabin pressure and oxygen and carbon dioxide mole fractions using the ideal gas law and Equations 1 and 7, respectively. Figure 1 shows the result of the computation for what we consider to be a large and small fire that burn approximately 3 and $0.5 \mathrm{~kg}$ of material, respectively.

Figure 1 shows the fire power (an input to the model) and the average cabin pressure, temperature and carbon dioxide and oxygen mole fractions as a function of time. The cabin pressure and temperature increase as the fire grows from time zero (zero fire power). As the gas temperature increases, the heat transfer to the walls (by radiation and convection) begins to increase, eventually exceeding the power of the fire. When this occurs the gas temperature and cabin pressure begin to decrease even if the fire continues to grow. The mole fractions of oxygen and carbon dioxide continuously increase with time until the fire is extinguished, at which time they remain constant.

The computation predicts that each of the fires will exceed the cabin pressure limitations. We assume that the pressure relief system on the vehicle would be sufficient to vent gas out of the vehicle to maintain structural integrity, although it would not be difficult to verify that assumption given the specifications of the relief valve. If, however, the rate of pressure rise exceeds the capability of the pressure relief system, the fire could compromise the spacecraft structure.

The ambient gas temperature for the large fire is disconcerting. The average (not peak) gas temperature exceeds limits for safe breathing even for a short time and would result in tracheal burning. In addition, the temperature could result in a hyperthermic condition for the crew, especially if their activity level were high (as would be expected in an emergency condition). The small fire results in a temperature environment that would surely be uncomfortable, but not likely life threatening.

The large fire also results in an environment that has oxygen and carbon dioxide concentrations that are considered either dangerous or lethal. The computation, however, does not assume any carbon dioxide removal or oxygen replenishment from the ECLSS systems. Again, the analysis could be easily updated given the specification of these systems. 

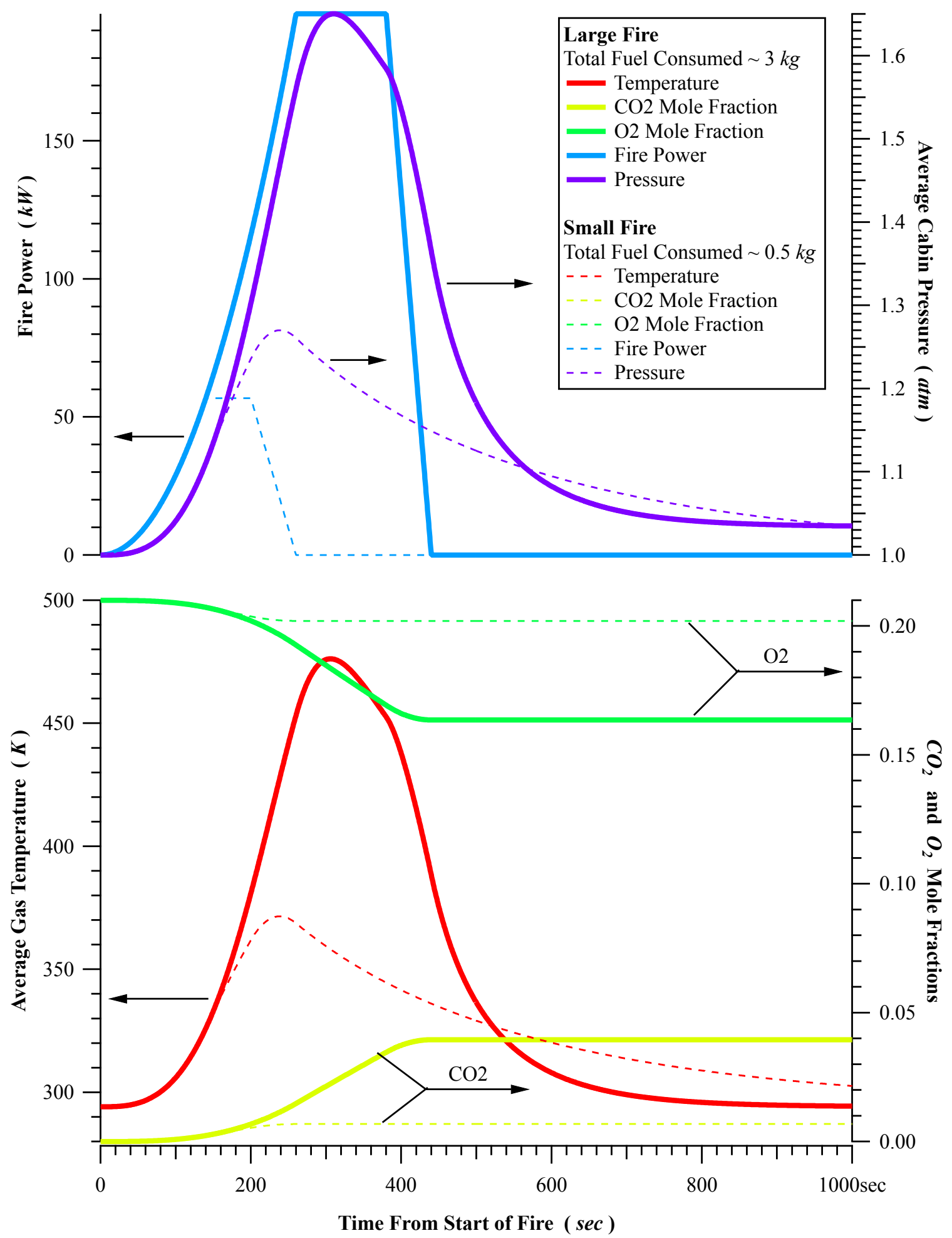

Figure 1. Predictions of average cabin gas temperature, pressure and oxygen and carbon dioxide mole fractions for an arbitrarily considered large and small fire. The graph shows the fire power profile assumed in the computation. 
Figure 2 shows the ambient gas temperature as a function of distance away from the flame using Equations 3 and 4 for a range of fire sizes. These results show the approximate spatial distribution of gas temperature whereas Figure 1 shows the volume-averaged gas temperatures. The results show that gas temperatures remain dangerously high at relatively large distances from the flame even for relatively small fires. These results may seem counterintuitive based on experience with terrestrial fires. The important fact to remember, however, is that for a terrestrial fire the gas temperature is very high above the flame owing to the buoyant flow $^{\mathrm{b}}$. The flame energy is omnidirectional in microgravity. Figure 2 does not account for any air circulation which would lower the temperature. The actual temperature at any radial location would be between the cabin-averaged gas temperature in Figure 1 and the spatially-resolved temperature in Figure 2. The results in Figure 2 therefore likely overestimate the gas temperature the crew would be exposed to.

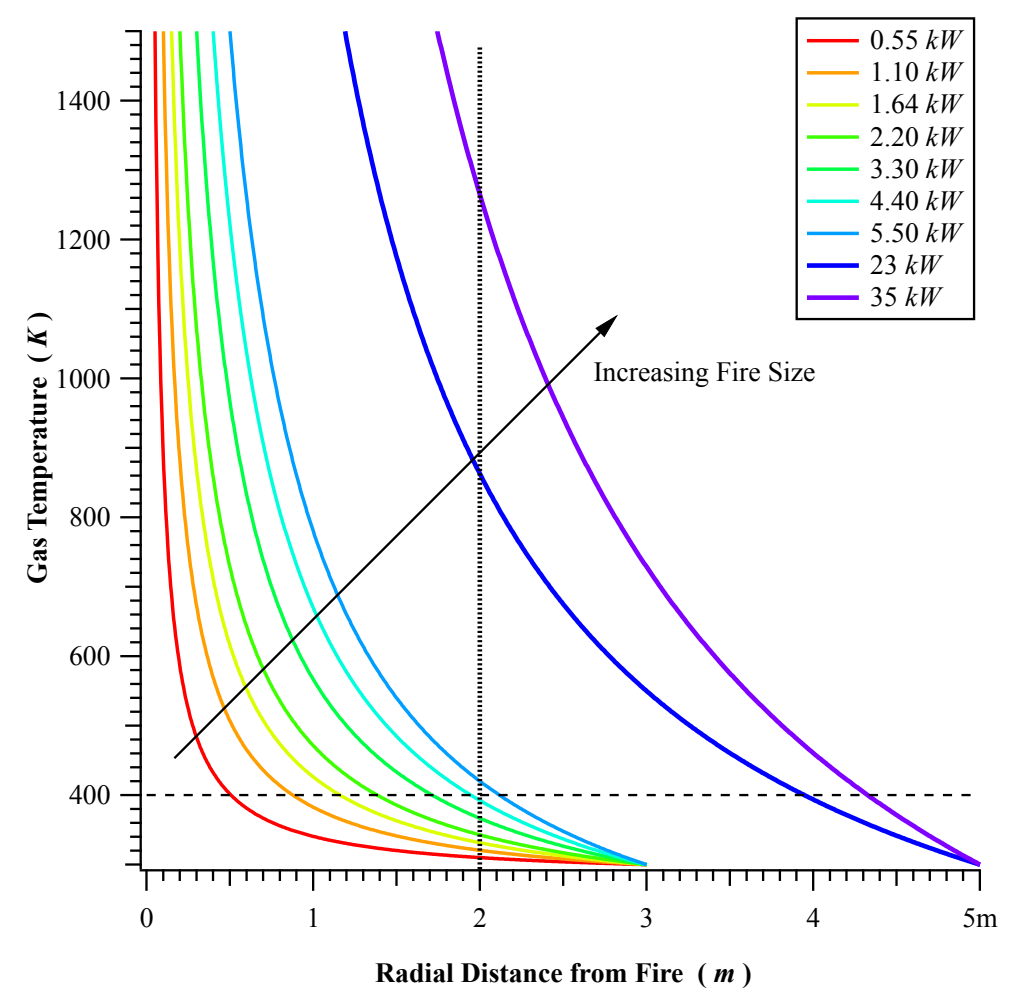

Figure 2. Gas temperature as a function of radial distance from the fire for a number of fire sizes. The analysis assumes a spherical flame at $1500 K$ with the radius of the fire determining the fire size. The dashed line at $400 K$ is the approximate limit for breathing without tracheal burning.

Figure 3 shows the maximum exposure time computed time using a heat flux from Equation with $\eta=1$ and the heat exposure data of Stoll and Chianta $^{8}$ for several radial distances from the flame. The exposure data required extrapolation for times longer than 30 seconds. The maximum exposure time is the time it would take for the crew to receive second degree burns from the fire. For reference, a reasonable distance to effectively fight a fire using a conventional handheld fire extinguisher would be approximately $2 \mathrm{~m}$. This simplified analysis shows that the crew could effectively fight a $100 \mathrm{~kW}$ fire for approximately $30 \mathrm{sec}$ before receiving second degree burns. During this time, the fire would be either diminished in size (in turn reducing the burn risk to the crew) or entirely extinguished.

Finally, Figures 4 and 5 show the predicted cabin temperature and mole fractions of carbon monoxide and carbon dioxide, respectively, as a function of fuel mass. The chemical equilibrium computation assumes adiabatic combustion of the fuel mass with cabin air with the fraction cabin air participating in the combustion $(\eta)$ varying between 0.01 and 0.3 to maintain the stoichiometry or unity equivalence ratio. The cabin temperature in Figure 4 is a bit higher than that in Figure 1 for the same fuel mass. This is because the chemical equilibrium neglects heat transfer, something that is explicitly included in the computation in Figure 1. The predicted temperatures, while higher than expected, again show the threat to the crew

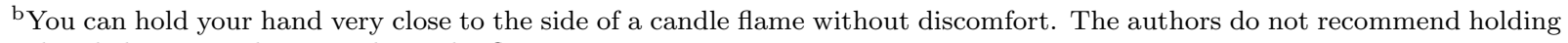
your hand that same distance above the flame.
} 


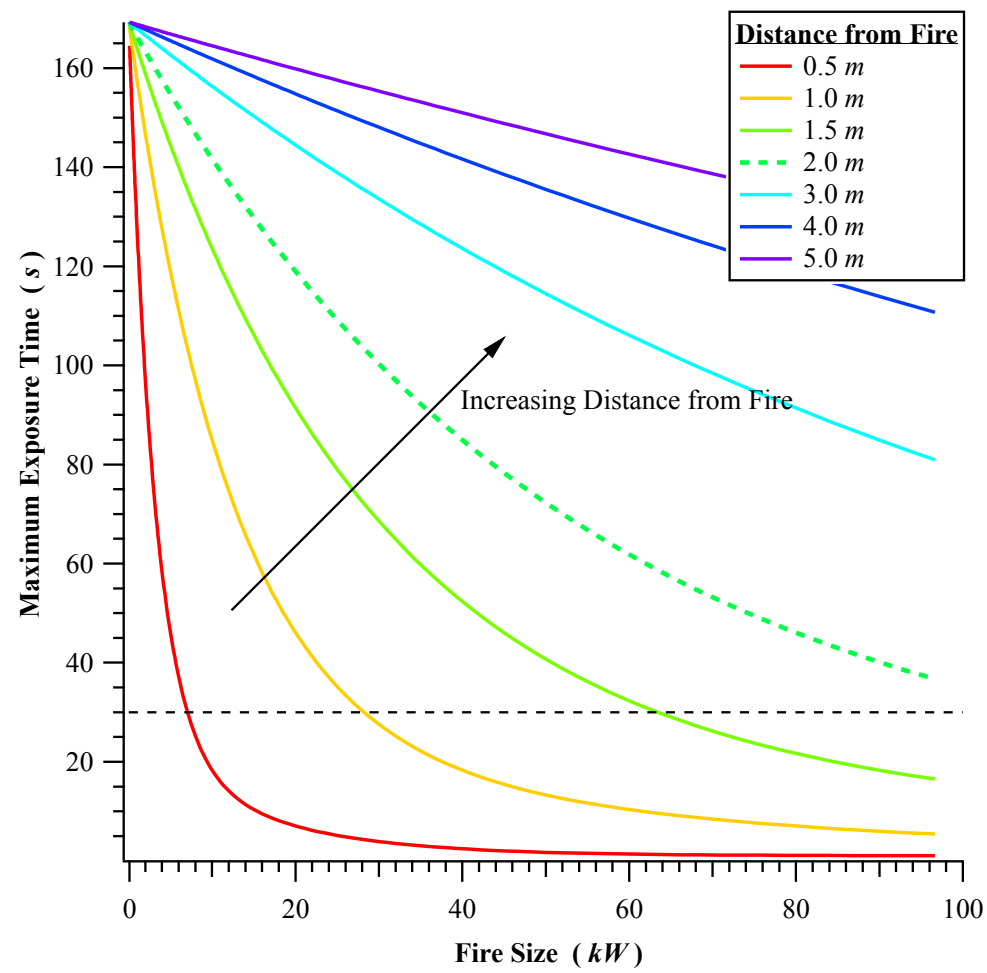

Figure 3. Exposure time as a function of fire size $(k W)$ for a number of radial distances from the fire. The simplified analysis assumes the energy is distributed in a hemisphere around the fire.

posed by most fires. The average temperatures for all but the smallest fires exceed the inhaled gas limit of approximately $400 \mathrm{~K}$.

The predictions in Figure 5 for carbon dioxide are in good agreement with those in Figure 1 for the transient combustion analysis. This serves as a good check for the transient analysis. Again, for all but the smaller fire sizes, the carbon dioxide mole fractions are high enough to warrant concern for the crew. The analysis again does not consider any carbon dioxide removal from the ECLSS systems.

The predictions in Figure 5 show that for almost all fire sizes considered, the carbon monoxide mole fraction is well above that which is considered safe for the crew. While it is expected that the crew will have emergency equipment to deal with carbon monoxide (i.e., a filtering respirator), the results highlight the need for such equipment. If emergency equipment, such as a respirator, were not available, carbon monoxide toxicity would be the crew hazard that most limited fire size. The results again neglect any removal of carbon monoxide by the ECLSS systems.

As a point of reference, it is useful to consider the Solid Fuel Oxygen Generator (SFOG) fire aboard the Russian Mir Orbiting Station. There exists, to the best of our knowledge, very little quantitative information about this fire. Cabin pressure readings during the fire are not available (at least to the authors). Assuming that the SFOG provided both the fuel (stainless steel) and oxidizer (oxygen), we can use the heat of combustion for stainless steel $(8.16 \mathrm{~kJ} / \mathrm{g})$. The fire power then requires the mass of stainless steel consumed and the time duration of the burn. The mass of material consumed is unknown. Examining the design we estimate (with very large error bars) approximately $0.15 \mathrm{~kg}$ of material consumed. Estimates of the total burn time also vary between 180 and $600 \mathrm{sec}$. If we assume a median value of $300 \mathrm{sec}$, the fire power was approximately $4 \mathrm{~kW}$, or much smaller than the small fire in Figure 1. The value, however, could be much higher (although still likely smaller than the peak power of the small fire in Figure 1) if a larger mass of metal was consumed. Also, for metal combustion it is not well known how much of the energy release goes into the gas phase and how much goes to raising the metal temperature (that eventually gets released to the gas phase, but over a MUCH longer time). Finally, given that the fuel was stainless steel and the SFOG provided oxygen, oxygen, carbon dioxide and carbon monoxide data is not all that relevant (and similarly unavailable). 


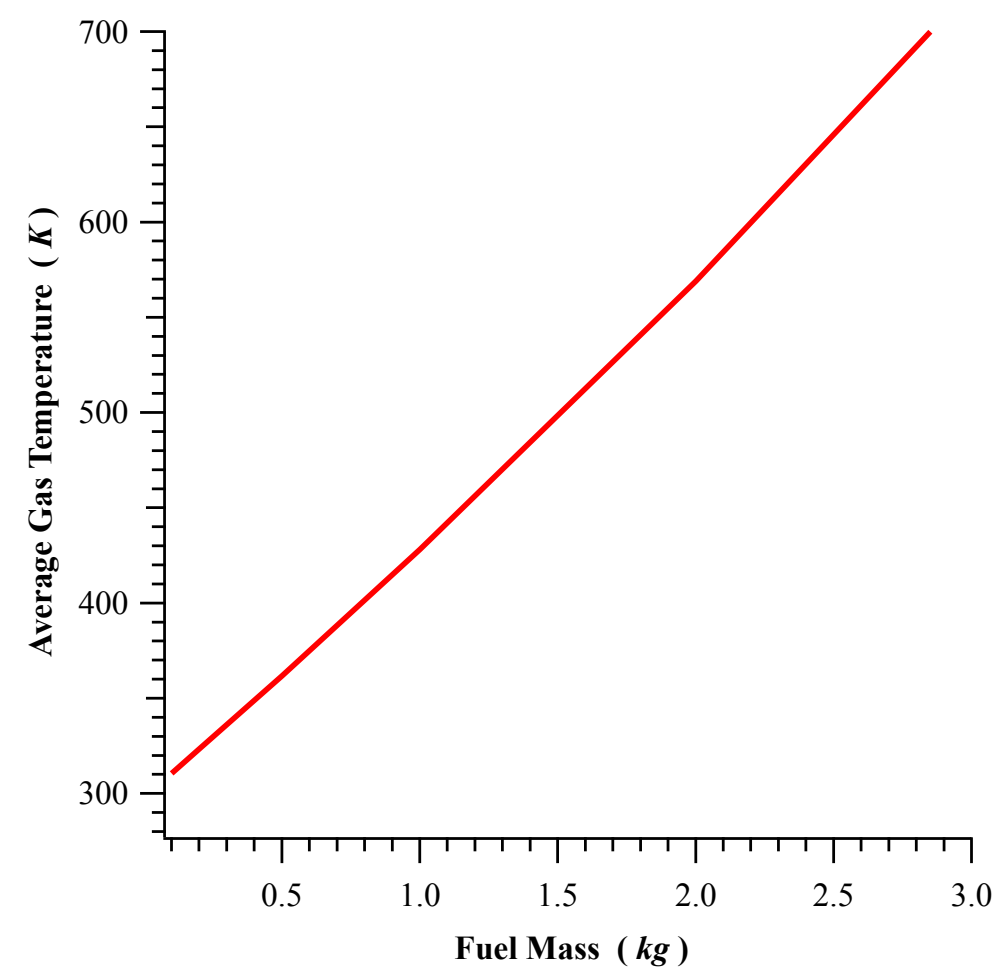

Figure 4. Average cabin temperature as a function of fuel mass (burned) computed assuming chemical equilibrium. The analysis assumes adiabatic combustion so the gas temperatures are higher than the heat transfer analysis in Figure 1.

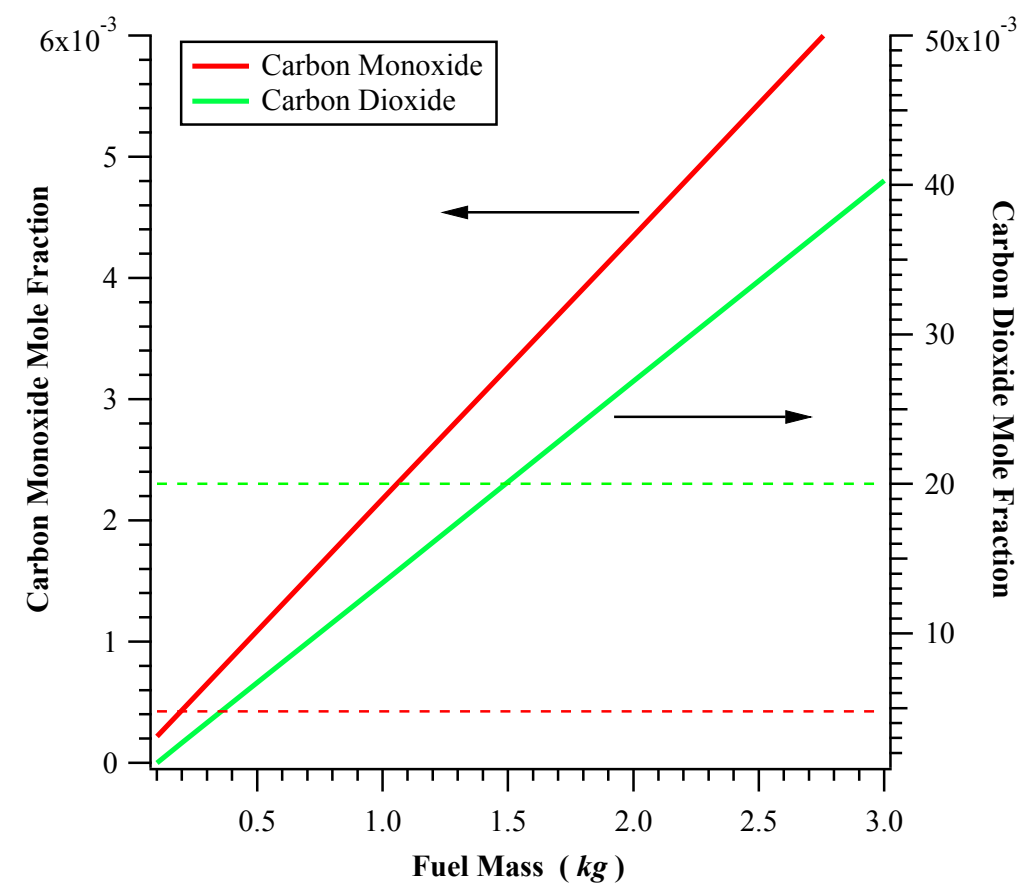

Figure 5. Average carbon monoxide and carbon dioxide mole fractions as a function of fuel mass assuming chemical equilibrium. The dashed lines are the 1 hour SMAC limits for carbon monoxide (425 ppm and carbon dioxide (0.02 mole fraction). 


\section{Conclusions}

This paper introduces the concept of a survivable fire for the purpose of fire extinguisher sizing and testing. The analysis considers the hazards to the crew from such things as over-pressure of the vehicle, excessive cabin temperatures and burns to the crew and exposure to toxic levels of combustion products and reduced oxygen. Simplified expressions are used to estimate these various quantities as a function of fire size.

A fire is considered 'survivable' if the gas temperatures, pressures carbon dioxide, carbon monoxide and oxygen partial pressures and heat flux in the vehicle remain below critical thresholds (except for oxygen where it must remain above the threshold). While these threshold levels are invariant with vehicle size, the time dependent quantities are strong functions of vehicle size; smaller vehicles having much smaller survivable fire sizes.

A sample analysis is conducted for a spacecraft the approximate size of the Destiny module on the ISS. The results show that fires involving $3 \mathrm{~kg}$ of fuel produce a maximum power of approximately $200 \mathrm{~kW}$. For fires of this size, there are multiple threats to the crew. The gas temperatures would likely burn the throat and lungs on inhalation and the result in hyperthermia over a long duration. The crew would also likely be burned if they were any reasonable distance from the fire. Finally, the oxygen, carbon dioxide and carbon monoxide mole fractions are all predicted to be nearly lethal.

For smaller fires that burn on the order of $0.5 \mathrm{~kg}$ of material (peak fire powers between 50 and $100 \mathrm{~kW}$ ) the fire would create uncomfortable, but not lethal, environmental conditions. The exception to that would be carbon monoxide production which emphasizes the need for some kind of respirator in the event of a fire.

The analysis could and should be extended to include the mitigating effects of the vehicle ECLSS systems. The pressure relief system will likely vent to maintain the vehicle pressure within safe limits. The crew could be on supplemental oxygen to mitigate the risk of hypoxic conditions. Further, carbon dioxide and carbon monoxide will eventually be removed from the cabin atmosphere to mitigate the dangers to the crew from toxic combustion by-products. Similarly, the vehicle heat rejection systems will eventually return the gas temperature to ambient values and protective gear could mitigate the hazards posed by exposure to excessive heat fluxes and gas temperatures. All of these mitigations will increase the size of a survivable fire, but require hardware and procedures to implement into the spacecraft. The analysis in this document allows design engineers to make rationale decisions regarding the safety hardware and procedures required for firefighting aboard a spacecraft. Finally, the analysis could also be extended to include other factors considered to be a risk to the crew.

\section{Acknowledgments}

The authors would like to acknowledge the assistance of P.V. Ferkul of the National Center for Space Exploration Research on fire size estimates.

\section{References}

${ }^{1}$ Dietrich, D. L., Ruff, G. A., and Urban, D. L., "Fundamentals of Fire Suppression in Reduced Gravity Environments," 38th International Conference on Environmental Systems, No. 2008-01-2087, Society for Automotive Engineers, San Francisco, California, July 2008.

${ }^{2}$ Dietrich, D. L., Ruff, G. A., Urban, D. L., Hicks, M. C., Stocker, D. P., Nayagam, V., and Takahashi, F., "Fire Suppression Technology in Human-Crewed Spacecraft - A Trade Study," 37th International Conference on Environmental Systems, No. 07ICES-112, Society for Automotive Engineers, Chicago, Illinois, July 2007.

${ }^{3}$ Dietrich, D. L., Ruff, G. A., and Urban, D. L., "A Fire Suppression Analysis for the Altair Project," 39th International Conference on Environmental Systems, No. 2009-01-2511, Society for Automotive Engineers, Savannah, Georgia, July 2009.

${ }^{4}$ Dietrich, D. L., Ruff, G. A., Easton, J. W., Abbott, A. A., Graf, J. C., Gianettino, D. P., and Sager, C. L., "Towards the Development of a Specification for a Portable Fine Water Mist Fire Extinguisher for Spacecraft Applications," 41st International Conference on Environmental Systems, No. AIAA-2011-5050, American Institute of Aeronautics and Astronautics, Portland, Oregon, July 2011.

${ }^{5}$ National Research Council, "Spacecraft Maximum Allowable Concentrations for Selected Airborne Contaminants," Tech. rep., National Research Council of the National Academies, Washington, DC, 2008.

${ }^{6}$ Huggett, C., "Estimation of Rate of Heat Release by Means of Oxygen Consumption Meausrements," Fire and Materials, Vol. 4, No. 2, 1980, pp. $61-65$.

${ }^{7}$ Walters, R. N., Hackett, S. M., and Lyon, R. E., "Heats of Combustion of High Temperatuyre Polymers," Fire and Materials, Vol. 24, No. 5, May 2000, pp. $245-252$.

${ }^{8}$ Stoll, A. M. and Chianta, M. A., "Method and Rating System for Evaluation of Thermal Protection," Aerospace Medicine, Vol. 40, 1969, pp. $1232-1238$. 
${ }^{9}$ Ozisik, M. N., Heat Transfer - A Basic Approach, McGraw Hill Book Company, New York, New York, 1985.

${ }^{10}$ Lva, Y.-G., Liua, J., and Zhang, J., "Theoretical evaluation of burns to the human respiratory tract due to inhalation of hot gas in the early stage of fires," Burns, Vol. 32, No. 4, June 2006, pp. $436-446$.

${ }^{11}$ Gokoglu, S. A., Niehaus, J. E., Olson, S. L., Dietrich, D. L., Ruff, G. A., Ferkul, P. V., and Johnston, M. C., "Prevention of Over-Pressurization During Combustion in a Sealed Chamber," 42nd International Conference on Environmental Systems, No. to appear, American Institute of Aeronautics and Astronautics, San Diego, California, July 2012.

${ }^{12}$ Gordon, S. and McBride, B. J., "Computer Program for Calculation of Complex Chemical Equilibrium Compositions and Applications. I. Analysis," NASA Reference Publication 1311, NASA John H. Glenn Research Center, Cleveland, Ohio, 1994.

${ }^{13}$ Custer, R. L. P. and Meacham, B. J., Introduction to Performance-Based Fire Safety, Society of Fire Protection Engineers and National Fire Protection Association, 1997.

11 of 11 